\title{
Data Downloads for Effective Noninvasive Ventilation in Patients With Neuromuscular Respiratory Failure
}

\author{
Jacqueline S Sandoz MD MSc FRCPC, Carole LeBlanc RRT, and \\ Douglas A McKim MD FRCPC DABSM
}

\section{Introduction}

Patients with progressive neuromuscular diseases, chest wall abnormalities, and diaphragmatic dysfunction are at high risk for the development of respiratory failure, with resulting morbidity and mortality. ${ }^{1} \mathrm{~A}$ large number of observational studies and a small number of randomized tri$a^{2} s^{2,3}$ have confirmed the effectiveness of noninvasive ventilation (NIV) in these individuals. Improvement in survival, 2,4-9 daytime symptoms of hypoventilation, quality of life, and arterial blood gases have all been documented. ${ }^{10,11}$ However, few details regarding how to initiate and, more importantly, how to follow these patients have been reported. Recommendations regarding optimal adjustment of settings such as ventilation mode (spontaneous, timed, spontaneous/timed, or pressure control), backup rate, inspiratory time $\left[\mathrm{T}_{\mathrm{I}}\right]$, and rise time, are rare in the literature.

At a minimum, regular (twice yearly) clinical follow-up of NIV settings, with measurement of daytime gas exchange to assess adequacy of ventilation, should be performed. ${ }^{12}$ If there are any concerns, overnight oximetry can be considered, as well as follow-up polysomnography with transcutaneous $\mathrm{P}_{\mathrm{CO}_{2}}$ monitoring. While early-morning arterial blood gas analysis may be helpful, arterial blood samples are logistically difficult to obtain and may not reflect an abnormal time course of $\mathrm{P}_{\mathrm{CO}_{2}}$ during the

\footnotetext{
The authors are affiliated with the Canadian Alternatives in Noninvasive Ventilation (CANVent) program, Ottawa Hospital Rehabilitation Centre, Division of Respiratory Medicine, Ottawa Hospital, Ontario, Canada. Dr McKim is also affiliated with the Faculty of Medicine, University of Ottawa, Ottawa, Ontario, Canada.
}

Ms LeBlanc has disclosed relationships with Philips Home Healthcare Solutions. The other authors have disclosed no conflicts of interest.

Correspondence: Jacqueline S Sandoz MD MSc FRCPC, Ottawa Hospital Rehabilitation Centre, Ottawa Hospital, 505 Smyth Road, Suite 1201, Ottawa, Ontario K1H 8M2 Canada. E-mail: jssandoz@yahoo.com.

DOI: $10.4187 /$ respcare. 02153 night. ${ }^{13}$ Janssens et $\mathrm{al}^{13}$ and McKim et al ${ }^{14}$ offer a further discussion on the monitoring of home NIV and some of the above-mentioned variables. ${ }^{13,14}$ As many of these patients have decreased mobility and difficulty accessing medical centers, we present other variables that can be followed while respecting patients' limited mobility and healthcare constraints.

Data downloaded from a home noninvasive ventilator can be used to estimate several variables and infer the extent of respiratory muscle rest. Currently available noninvasive ventilators record usage data to monitor adherence, and neuromuscular respiratory care teams are increasingly using this data-collection capability, albeit with little guidance from the literature.

We discuss a case that illustrates the importance of combining appropriate follow-up and clinical care with adjustment of ventilation variables based on home-ventilator data, to increase patient comfort and adherence, decrease work of breathing, improve gas exchange, and ultimately, prolong tracheostomy-free survival.

\section{Case Summary}

A 23-year-old male with Duchenne muscular dystrophy was referred to our out-patient clinic after having been advised to undergo a tracheostomy at another center. $\mathrm{He}$ was wheelchair-assisted and was attending college fulltime, despite severe weakness and pulmonary restriction, dyspnea, frequent nocturnal awakening, morning headaches, production of viscous white sputum throughout the night, ineffective cough, and weight loss. He had been on noninvasive ventilation (Synchrony, Philips Home Healthcare Solutions, Monroeville, Pennsylvania) for 11 months, and his ventilation settings had been established in a sleep laboratory. All noninvasive ventilators with backup rates in our healthcare system are publicly funded, and there is no proprietary interest in any one type over any other.

Despite excellent adherence ( $>86 \%$ of days used, and $>9$ h usage per day), his daytime $\mathrm{P}_{\mathrm{aCO}}$ was $75 \mathrm{~mm} \mathrm{Hg}$, and his $\mathrm{P}_{\mathrm{aO}}$ was $74 \mathrm{~mm} \mathrm{Hg}$. Table 1 shows his respiratory 


\section{Data Downloads for Effective Noninvasive Ventilation}

Table 1. Forced Vital Capacity and Downloaded Ventilator Data From the Nights Leading Up to the Clinic Visits

\begin{tabular}{|c|c|c|c|c|c|c|c|c|c|c|c|c|}
\hline Visit & $\begin{array}{c}\text { FVC } \\
\text { L } \\
\text { (\% of } \\
\text { predicted) }\end{array}$ & $\begin{array}{l}\text { Ventilation } \\
\text { Mode }\end{array}$ & $\begin{array}{l}\text { Inspiratory } \\
\text { Pressure } \\
\mathrm{cm} \mathrm{H}_{2} \mathrm{O}\end{array}$ & $\begin{array}{l}\text { Expiratory } \\
\text { Pressure } \\
\mathrm{cm} \mathrm{H}_{2} \mathrm{O}\end{array}$ & $\begin{array}{c}\text { Backup } \\
\text { Rate } \\
\text { breaths/min }\end{array}$ & $\begin{array}{l}\text { Inspiratory } \\
\text { Time } \\
\text { s }\end{array}$ & $\begin{array}{c}\text { Rise } \\
\text { Time } \\
1-6 \\
\text { scale }\end{array}$ & $\begin{array}{c}\text { Use Per } \\
\text { Day } \\
\text { h:min }\end{array}$ & $\begin{array}{c}\text { Tidal } \\
\text { Volume } \\
\text { mL }\end{array}$ & $\begin{array}{c}\text { Minute } \\
\text { Ventilation } \\
\text { L }\end{array}$ & $\begin{array}{c}\% \\
\text { Spontaneous } \\
\text { Breaths }\end{array}$ & $\begin{array}{c}\mathrm{P}_{\mathrm{CO}_{2}} \\
\mathrm{~mm} \mathrm{Hg}\end{array}$ \\
\hline $1 \mathrm{~A}^{*}$ & Unknown & Spontaneous/timed & 12 & 7 & 17 & 1.2 & 3 & 9:09 & 269 & 5.1 & 84 & Unknown \\
\hline 1B & $0.60(13)$ & Spontaneous/timed & 18 & 8 & 17 & 1.2 & 3 & 9:00 & 273 & 4.8 & 36 & 75 \\
\hline 2 & $0.73(15)$ & Pressure control & 18 & 8 & 16 & 1.6 & 1 & $10: 19$ & 360 & 5.6 & 15 & 57 \\
\hline 3 & $0.75(15)$ & Pressure control & 21 & 8 & 16 & 1.7 & 1 & 10:02 & 460 & 7.1 & 8 & $36 \dagger$ \\
\hline
\end{tabular}

function, $\mathrm{P}_{\mathrm{CO}_{2}}$, and ventilator settings over the course of his out-patient visits.

Prior to his first visit with our clinic (see Table 1, visit 1A) the data from his ventilator demonstrated a low mean tidal volume $\left(\mathrm{V}_{\mathrm{T}}\right)(269 \mathrm{~mL})$ and a high proportion of patienttriggered breaths (84\%) suggesting sustained neuromechanical drive to breathe during sleep. A few weeks prior to his first appointment at our center, his inspiratory pressure setting had been increased from $12 \mathrm{~cm} \mathrm{H}_{2} \mathrm{O}$ to $18 \mathrm{~cm} \mathrm{H}_{2} \mathrm{O}$, and his expiratory pressure setting from $7 \mathrm{~cm} \mathrm{H}_{2} \mathrm{O}$ to $8 \mathrm{~cm} \mathrm{H}_{2} \mathrm{O}$, increasing his pressure support to $10 \mathrm{~cm} \mathrm{H}_{2} \mathrm{O}$. Interestingly, this change did not increase his $\mathrm{V}_{\mathrm{T}}$ or minute ventilation $\left(\dot{\mathrm{V}}_{\mathrm{E}}\right)$. However, the average percentage of patient-triggered breaths decreased from $84 \%$ to $36 \%$, suggesting an increased contribution from the ventilator to achieve a similar $\dot{\mathrm{V}}_{\mathrm{E}}$ (see Table 1, visit 1B). Figure 1 shows the patient's initial ventilator-data download summary in graphic format.

We felt that his NIV settings could be further optimized to improve alveolar ventilation and decrease patient effort. His ideal body weight was $68 \mathrm{~kg}$, and our intention was to achieve a $\mathrm{V}_{\mathrm{T}}$ of approximately $10 \mathrm{~mL} / \mathrm{kg},{ }^{15}$ though understanding that, due to severe thoracic restriction, this goal would only be achieved gradually, if at all. Detailed ventilator adjustments are provided below.

\section{Ventilation Mode}

In general, noninvasive ventilators allow cycling at a specific time (time-cycled) or flow (flow-cycled) in the spontaneous, spontaneous/timed, timed, and pressure control modes. The Synchrony's Digital Auto-Track Sensitivity algorithm uses flow triggering and cycling only during spontaneous breaths. In the spontaneous mode the algorithm responds to patient-initiated inspiratory efforts, triggering the inspiratory pressure and cycling to expiratory pressure when the algorithm-determined decrease in the inspiratory flow is detected. The timed mode offers machine-delivered breaths determined by the set breathing rate, and cycles to expiration based on the set $\mathrm{T}_{\mathrm{I}}$, not by the
Digital Auto-Track Sensitivity algorithm. The spontaneous/timed mode combines spontaneous and timed modes features. In spontaneous/timed mode the patient receives a minimum number of breaths per minute, determined by the breath rate setting or backup rate. The spontaneous/ timed mode machine-delivered breath duration is controlled by the $T_{I}$ setting (time-cycled); however, the duration of the patient-triggered breaths remain determined by the Digital Auto-Track Sensitivity algorithm as inspiratory flow decreases, not by any pre-set $\mathrm{T}_{\mathrm{I}}$. The Synchrony's pressure-controlled mode ensures that both machinetriggered and patient-triggered breaths are time-cycled, controlled by the $T_{I}$ setting. ${ }^{16}$ Other noninvasive ventilators, such as the ResMed VPAP STA III, do not have a pressurecontrolled mode. However, it is possible to control for $T_{I}$ with the minimum and maximum inspiratory pressure while in the spontaneous/timed mode. This feature allows adjustment of the minimum and maximum time that inspiratory pressure will be delivered, which enables more control of the $T_{I}$ and prevents premature cycling. This detail is critical when ventilating patients with restrictive disease, in whom a rapid reduction in inspiratory flow occurs due to decreased lung and chest wall compliance. Rapid flow reduction will prematurely cycle the ventilator during spontaneous breaths, reducing the time over which optimal inspiratory pressure is applied, shortening $T_{I}$ and reducing $\mathrm{V}_{\mathrm{T}}$. One way to address this limitation is with the Synchrony's pressure control mode, in which the inspiratory pressure is sustained for the duration of the set $\mathrm{T}_{\mathrm{I}}$, to a maximum of $3.0 \mathrm{~s}$ (default). Inverse inspiratory/ expiratory ratio ventilation is not permitted. In short, an increased $\mathrm{V}_{\mathrm{T}}$ can be obtained by prolonging and controlling the $\mathrm{T}_{\mathrm{I}}$, which we achieved in our patient by changing from Synchrony's spontaneous/timed mode to its pressure-controlled mode. Although simply prolonging the $T_{I}$ may improve the $\dot{V}_{E}$ in spontaneous/timed mode, it's effectiveness will be impacted by the fraction of machinetriggered versus patient-triggered breaths, as only the machine-triggered breaths would benefit from the set $T_{I}$. 


\section{Data Downloads for EfFective Noninvasive Ventilation}
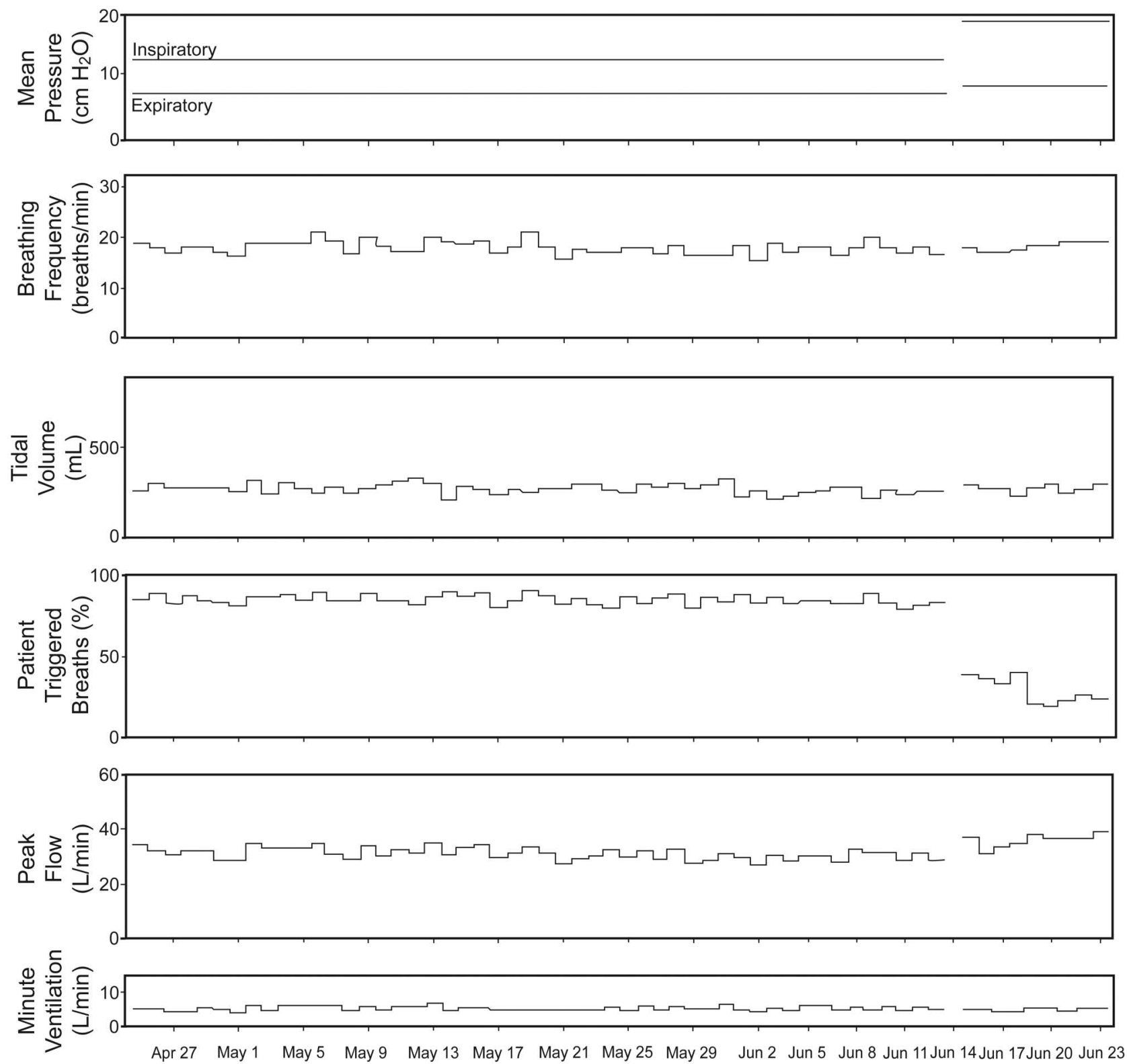

Fig. 1. Downloaded ventilator data from visit 1. On June 17 the inspiratory and expiratory pressure were increased, and the percentage of patient-triggered breaths decreased to $35 \%$, but there was no change in tidal volume or minute ventilation. The portion of the graph prior to the pressure change corresponds to row $1 \mathrm{~A}$ in Table 1, and the portion after the pressure change corresponds to row $1 \mathrm{~B}$.

\section{Pressure Support}

Our patient's inspiratory and expiratory pressure had recently been increased. To avoid further pressure increases, which had resulted in little improvement in $\dot{\mathrm{V}}_{\mathrm{E}}$, we changed the ventilation mode to pressure-controlled, which we anticipated to provide more benefit. Additional pressure support could be added subsequently if required.

\section{Inspiratory Time}

We anticipated that increasing the $T_{\mathrm{I}}$ from $1.2 \mathrm{~s}$ in the spontaneous/timed mode to $1.6 \mathrm{~s}$ (closer to a 1/1 inspiratory/ expiratory ratio) in the pressure-controlled mode would increase the $\mathrm{V}_{\mathrm{T}}$. As there is generally little or no impediment to expiratory flow, an inspiratory/expiratory ratio of $1 / 1$ is recommended in patients with neuromuscular disease. ${ }^{12}$ 


\section{Data Downloads for Effective Noninvasive Ventilation}

\section{Backup Rate}

We reduced the backup rate from 17 to 16 breaths/min, to allow for the increased $\mathrm{T}_{\mathrm{I}}$.

\section{Rise Time}

The rise time is usually adjusted to patient comfort. A faster rise time may help maximize $\mathrm{V}_{\mathrm{T}}$, but may be uncomfortable, increase mask leak, or cause aerophagia. ${ }^{12}$ Our patient was able to tolerate a short rise time setting of $1(100 \mathrm{~ms})$ during a trial in the clinic with the respiratory therapist.

Changes to achieve further improvements in ventilation and $\mathrm{P}_{\mathrm{CO}_{2}}$ could be introduced during subsequent visits, as required. Although a more sustained $\mathrm{T}_{\mathrm{I}}$ may improve nocturnal ventilation, lung recruitment, and atelectasis, regular lung volume recruitment maneuvers with a modified manual resuscitation bag (often referred to as breath-stacking) were also initiated to improve lung compliance and cough efficiency. ${ }^{14,17}$ Use of the CoughAssist device (Philips Home Healthcare Solutions, Monroeville, Pennsylvania) was re-emphasized to aid in secretion clearance. ${ }^{18}$

Two weeks after our initial meeting the patient reported by telephone that he was now able to sleep through most nights without calling to be turned, compared to 4 or 5 times a night previously. He felt more alert and refreshed during the day, and his appetite improved. His overnight $\mathrm{S}_{\mathrm{pO}_{2}}$ was well over $95 \%$ throughout the night.

His second visit, 2 months later, is summarized in Table 1 and Figure 2. His FVC had increased by $130 \mathrm{~mL}$, to $0.73 \mathrm{~L}$ (15\% of predicted), and his $\mathrm{P}_{\mathrm{aCO}}$ had also improved to $57 \mathrm{~mm} \mathrm{Hg}$. His $\mathrm{V}_{\mathrm{T}}(360 \mathrm{~mL}), \mathrm{V}_{\mathrm{E}}(5.6 \mathrm{~L})$, and percentage of patient-triggered breaths $(15 \%)$ had all improved. The optimal $\mathrm{V}_{\mathrm{T}}$ was difficult to achieve, likely due to marked reduction in chest wall compliance; however, overall ventilation had improved with a reduction in patient-effort (based on patient-triggered breaths).

After reviewing the downloaded ventilator data we again attempted to increase the alveolar ventilation, by increasing the inspiratory pressure to $21 \mathrm{~cm} \mathrm{H}_{2} \mathrm{O}$ (pressure support of $13 \mathrm{~cm} \mathrm{H}_{2} \mathrm{O}$ ) and the $\mathrm{T}_{\mathrm{I}}$ to $1.7 \mathrm{~s}$. Despite symptomatic and objective improvements in nocturnal ventilation, persistent daytime hypercapnia and symptoms prompted the introduction of daytime mouthpiece ventilation at this visit. ${ }^{19,20}$

His third visit, 10 months later, is also summarized in Table 1. The $\mathrm{V}_{\mathrm{T}}, \dot{\mathrm{V}}_{\mathrm{E}}$, and patient-triggered breaths improved, and the patient was very comfortable with his nocturnal ventilator settings. His end-tidal $\mathrm{P}_{\mathrm{CO}_{2}}$ had improved to $36 \mathrm{~mm} \mathrm{Hg}$. He was also using mouthpiece ventilation throughout the day, and had avoided tracheostomy, while improving his respiratory function and ventilation. Optimizing the ventilator settings certainly contributed to his overall improvement. Improved daytime ventilation via mouthpiece, enhanced secretion clearance with the CoughAssist, and possibly increased lung compliance from lung volume recruitment also contributed positively. Although discussion of these complementary therapies is beyond the scope of this paper, the importance of complete respiratory care and follow-up in these patients cannot be over-emphasized. ${ }^{14,17,18,21,22}$ The patient has still not required a tracheostomy, more than 7 years after it was originally recommended.

\section{Discussion}

While there is minimal evidence for the choice of one ventilation setting change over another, it is accepted that higher pressures are less well tolerated. ${ }^{23}$ Before increasing the pressures, attention to other settings may improve ventilation, comfort, adherence, and asynchrony. We present one way these goals (increase alveolar ventilation, improve nocturnal muscle rest to allow for adequate spontaneous daytime ventilation, and avoid tracheostomy) can be achieved.

In this clinical setting, the first goal was to improve alveolar ventilation, documented by the downloaded ventilator data. Improved alveolar ventilation was achieved by increasing and controlling the $T_{I}$ by changing to the pressure-controlled mode, and by reducing the rise time to reach the inspiratory pressure faster. This improved $\mathrm{P}_{\mathrm{aCO}_{2}}$ from $75 \mathrm{~mm} \mathrm{Hg}$ to $57 \mathrm{~mm} \mathrm{Hg}$. Only after these settings were optimized was an increase in pressure support introduced.

The improved alveolar ventilation decreased the spontaneous respiratory muscle activity, as inferred by a decrease in the percentage of patient-triggered breaths, from $84 \%$ to $15 \%$, and finally to $8 \%$. This was accomplished despite a decrease in the breathing frequency. In patients with respiratory failure from neuromuscular disease, it is a reasonable goal to minimize the percentage of spontaneous breaths, to maximize muscle rest, because a substantial amount of patient effort is employed during spontaneous breaths, even if mechanically assisted. ${ }^{12,24}$ Although we did not measure the work of breathing in our patient, reduced work of breathing is inferred by the reduced percentage of spontaneous breaths. However, we must cautiously interpret patient-triggered breaths, because a weak inspiratory effort may not trigger the ventilator, which would cause a falsely low percentage of patient-triggered breaths. Clinically, however, this would likely be associated with asynchrony, desaturation, and patient discomfort, without an improvement in ventilation. ${ }^{25}$ Reducing the expiratory pressure to increase the overall pressure support can also be considered, to increase the $\mathrm{V}_{\mathrm{T}}$. We assumed that the set expiratory pressure, determined by level-1 polysomnography in a center that specializes in 

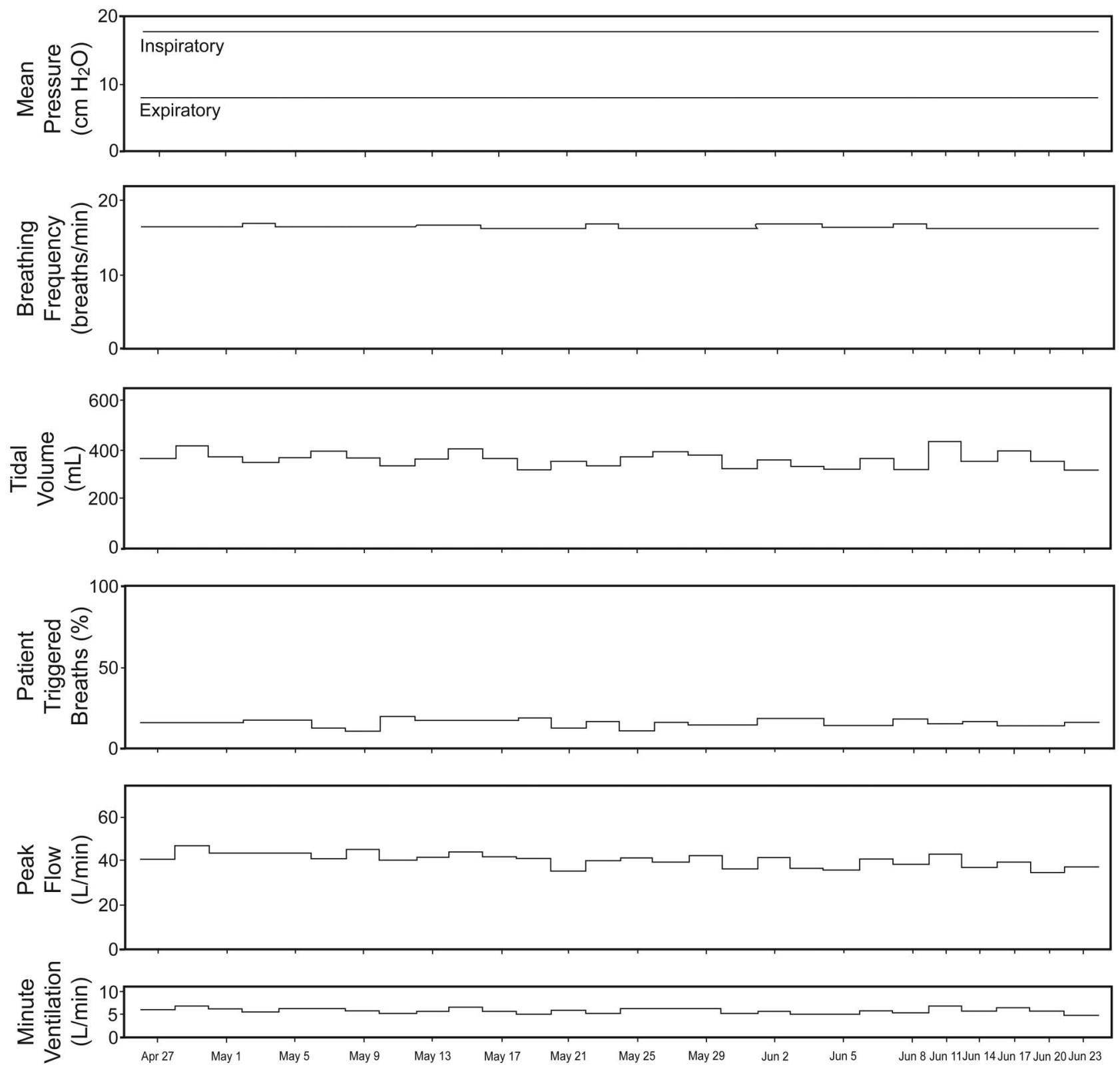

Fig. 2. Downloaded ventilator data from visit 2 (see Table 1) shows improvements in tidal volume, minute ventilation, and percentage of spontaneous breaths, with no changes in the inspiratory or expiratory pressure, compared to Figure 1.

neuromuscular patients, was applied to relieve a degree of obstructive apnea, as per American Academy of Sleep Medicine guidelines, so this alternative was not chosen. ${ }^{26}$

Avoiding tracheostomy, the third goal, was achieved by optimizing nocturnal ventilation and muscle rest to improve daytime ventilation. In addition, the introduction and reinforcement of lung volume recruitment techniques to improve lung and chest wall compliance, and CoughAssist to clear secretions, are important in the management of neuromuscular disease. Finally, introducing daytime mouthpiece ventilation when other measures become in- adequate can provide 24-hour ventilation while avoiding tracheostomy.

\section{Teaching Points}

- Downloaded ventilator data can help identify causes of hypoventilation. Keeping in mind that such data do not provide direct evidence of hypoventilation, the data should be reviewed in parallel with the patient's signs and symptoms when making adjustments to improve $\mathrm{V}_{\mathrm{T}}, \dot{\mathrm{V}}_{\mathrm{E}}$, comfort, and adherence.

- Improvements in alveolar ventilation can be achieved by 


\section{Data Downloads for Effective Noninvasive Ventilation}

controlling $\mathrm{T}_{\mathrm{I}}$. Different ventilators accomplish this in different ways, but overall the change prevents premature cycling: a common problem in restrictive disorders.

- Shortening the rise time, if tolerated by the patient, can increase the time at maximum inspiratory pressure within a set $T_{I}$, which can increase $V_{T}$.

- Reducing the backup rate may also be required to maintain a longer $\mathrm{T}_{\mathrm{I}}$ and inspiratory/expiratory of 1/1.

- The percentage of patient-triggered breaths can be followed as an indirect measure of nocturnal muscle rest.

- Complete care of the patient with neuromuscular disease also includes measures to assist in lung volume recruitment and secretion clearance.

\section{REFERENCES}

1. Hill NS. Ventilator management for neuromuscular disease. Semin Respir Crit Care Med 2002;23(3):293-305.

2. Bourke SC, Tomlinson M, Williams TL, Bullock RE, Shaw PJ, Gibson GJ. Effects of non-invasive ventilation on survival and quality of life in patients with amyotrophic lateral sclerosis: a randomised controlled trial. Lancet Neurol 2006;5(2):140-147.

3. Ward S, Chatwin M, Heather S, Simonds AK. Randomised controlled trial of non-invasive ventilation (NIV) for nocturnal hypoventilation in neuromuscular and chest wall disease patients with daytime normocapnia. Thorax 2005;60(12):1019-1024.

4. Aboussouan LS, Khan SU, Meeker DP, Stelmach K, Mitsumoto H. Effect of noninvasive positive-pressure ventilation on survival in amyotrophic lateral sclerosis. Ann Intern Med 1997;127(6):450-453.

5. Bach JR. Amyotrophic lateral sclerosis: prolongation of life by noninvasive respiratory AIDS. Chest 2002;122(1):92-98.

6. Kihira T, Yoshida S, Okamoto K, Kazimoto Y, Ookawa M, Hama K, et al. Survival rate of patients with amyotrophic lateral sclerosis in Wakayama Prefecture, Japan, 1966 to 2005. J Neurol Sci 2008; 268(1-2):95-101.

7. Kleopa KA, Sherman M, Neal B, Romano GJ, Heiman-Patterson T. Bipap improves survival and rate of pulmonary function decline in patients with ALS. J Neurol Sci 1999;164(1):82-88.

8. Yasuma F, Sakai M, Matsuoka Y. Effects of noninvasive ventilation on survival in patients with Duchenne's muscular dystrophy. Chest 1996;109(2):590.

9. Annane D, Chevrolet JC, Chevret S, Raphael JC. Nocturnal mechanical ventilation for chronic hypoventilation in patients with neuromuscular and chest wall disorders. Cochrane Database Syst Rev 2000;(2)(2):CD001941.
10. Bourke SC, Bullock RE, Williams TL, Shaw PJ, Gibson GJ. Noninvasive ventilation in ALS: indications and effect on quality of life. Neurology 2003;61(2):171-177.

11. Farrero E, Prats E, Povedano M, Martinez-Matos JA, Manresa F, Escarrabill J. Survival in amyotrophic lateral sclerosis with home mechanical ventilation: the impact of systematic respiratory assessment and bulbar involvement. Chest 2005;127(6):2132-2138.

12. Robert D, Argaud L. Clinical review: long-term noninvasive ventilation. Crit Care 2007;11(2):210.

13. Janssens JP, Borel JC, Pepin JL, SomnoNIV Group. Nocturnal monitoring of home non-invasive ventilation: the contribution of simple tools such as pulse oximetry, capnography, built-in ventilator software and autonomic markers of sleep fragmentation. Thorax 2011; 66(5):438-445.

14. McKim DA, Road J, Avendano M, Abdool S, Cote F, Duguid N, et al. Home mechanical ventilation: a Canadian Thoracic Society clinical practice guideline. Can Respir J 2011;18(4):197-215.

15. Wilkins RL, Stoller JK, Scanlon CL. Egan's fundamentals of respiratory care, 8th edition. St Louis: Elsevier; 2003.

16. Respironics. BiPAP Synchrony provider manual 2002. http://www. ontvep.ca/pdf/synchrony_clinical.pdf. Accessed January 6, 2014.

17. McKim DA, Katz SL, Barrowman N, Ni A, LeBlanc C. Lung volume recruitment slows pulmonary function decline in Duchenne muscular dystrophy. Arch Phys Med Rehabil 2012;93(7):1117-1122.

18. Bach JR. Update and perspective on noninvasive respiratory muscle aids. Part 2: the expiratory aids. Chest 1994;105(5):1538-1544.

19. McKim DA, Griller N, Leblanc C, Woolnough A, King J. Twentyfour hour noninvasive ventilation in Duchenne muscular dystrophy: a safe alternative to tracheostomy. Can Respir J 2013;20(1):e5-e9.

20. Toussaint M, Steens M, Wasteels G, Soudon P. Diurnal ventilation via mouthpiece: survival in end-stage Duchenne patients. Eur Respir J 2006;28(3):549-555.

21. Bach JR. Update and perspectives on noninvasive respiratory muscle aids. Part 1: the inspiratory aids. Chest 1994;105(4):1230-1240.

22. Bach JR, Alba AS, Saporito LR. Intermittent positive pressure ventilation via the mouth as an alternative to tracheostomy for 257 ventilator users. Chest 1993;103(1):174-182.

23. Vitacca M, Bianchi L, Zanotti E, Vianello A, Barbano L, Porta R, et al. Assessment of physiologic variables and subjective comfort under different levels of pressure support ventilation. Chest 2004;126(3): 851-859.

24. Marini JJ, Capps JS, Culver BH. The inspiratory work of breathing during assisted mechanical ventilation. Chest 1985;87(5):612-618.

25. Fanfulla F, Delmastro M, Berardinelli A, Lupo ND, Nava S. Effects of different ventilator settings on sleep and inspiratory effort in patients with neuromuscular disease. Am J Respir Crit Care Med 2005; 172(5):619-624.

26. Kushida CA, Chediak A, Berry RB, Brown LK, Gozal D, Iber C, et al. Clinical guidelines for the manual titration of positive airway pressure in patients with obstructive sleep apnea. J Clin Sleep Med 2008;4(2):157-171. 